\title{
HT2003-47311
}

\section{NATURAL SMOLDERING OF CIGARETTES}

\author{
Fernando de Souza Costa \\ Laboratório Associado de Combustão e Propulsão \\ Instituto Nacional de Pesquisas Espaciais \\ Cachoeira Paulista, São Paulo, 12630-000, Brazil \\ fernando@lcp.inpe.br
}

\begin{abstract}
The smoldering of cigarettes without drawing is described by a simple analytical model. A burning cigarette is assumed to be divided in 4 zones: unburned tobacco, dry tobacco, char and ash, separated by infinitesimally thin fronts of drying, pyrolysis and char oxidation. Circumferential heat losses and the convective-diffusive processes in the boundary layer are considered. A set of non-linear algebraic equations is solved to determine smoldering rates, drying lengths and pyrolysis lengths and to obtain the profiles of temperature. The influence coefficients of several parameters on smolder characteristics are calculated. Theoretical burn rates have shown a good agreement to experiments.
\end{abstract}

\section{INTRODUCTION}

Smoldering of cigarettes is a major cause of household and forest fires. According to Ohlemiller et al. [1] most deaths in fires in the US are a consequence of the ignition of soft furnishings by cigarettes. Therefore it is important to predict cigarette burning behaviour to reduce fire hazards.

Several researchers studied the mechanism of smoldering in cigarettes. Smoldering is defined as a flameless burning process occurring in charring materials.

Egerton et al. [2] developed a theoretical one-dimensional model of smoldering cigarettes with puffing. Their model predicted an unstable shape of the smoldering front in time which is not verified experimentally. They measured temperature profiles using $x$-ray pyrometry, the distribution of hot gases by schlieren photography and consumption patterns for a variety of smoking conditions.

Gugan [3] predicted the combustion zone shape in a simplified diffusion controlled model and determined burning rates during puffs 10 times larger than between puffs (no draw), and found a calorific value for tobacco/air stoichiometry of $15740 \mathrm{~kJ} / \mathrm{kg}$.

Summerfield et al. [4] developed a steady-draw onedimensional model assuming a one-step char oxidation reaction and one-step pyrolysis. They compared model predictions of the effects of flow rate and oxygen concentration on burning rate and pressure drop with experiments and found a good agreement.

Muramatsu et al. [5] developed a one-dimensional mathematical model of the evaporation-pyrolysis processes inside a naturally smoldering cigarette, considering Arrhenius kinetics for evaporation of water and pyrolysis of tobacco, volumetric char oxidation, internal heat transfer, using an effective thermal conductivity, and considering heat losses due to free convection and radiation. They identified a pyrolysisevaporation zone range of 373-773 K and measured temperature profiles using thermocouples and density profiles using $\beta$ radiation, obtaining a good agreement with the theoretical values.

Muramatsu [6] determined several physical characteristics of tobacco during smoldering, such as specific heats, thermal diffusivities and heat released. The amounts of oxygen consumed and carbon oxide formed during smoldering were measured. A two-dimensional theoretical model was developed, yielding a good agreement to experimental results. The natural smolder rates measured were about 26 times slower than smolder rates with puffing, with $65 \%$ of the carbon in the cigarettes converted to $\mathrm{CO}$ and $\mathrm{CO}_{2}$, generating 6 to 10 moles of $\mathrm{CO}_{2}$ for each mol of $\mathrm{CO}$ produced.

Gann et al. [7] developed a two dimensional computer model (CIGARET 25) to predict the temperature and density profiles inside a cigarette. Their research project comprised several studies related to cigarette smoldering, ranging from computational, fundamental to empirical.

Mitler and Walton [8] developed a computer model (CIGARET) to calculate the time-dependent behavior of a cigarette smoldering quietly in the air, away from surfaces. The model incorporated diffusion and convection of gases, as well as the kinetics of char oxidation. The internal heat fluxes, as well as the internal distributions of temperatures, gas velocity and oxygen concentration, were calculated.

Costa [9] developed an analytical model for a smoldering cigarette with no draw considering a single front of drying and pyrolysis, circumferential heat losses and the diffusiveconvective processes in the boundary layer. Expressions for burn rates, temperature profiles and positions of reaction fronts 
were obtained. The theoretical results presented a good agreement to experiments.

This work extends the previous model by Costa [9] with the consideration of separate fronts of drying, pyrolysis and char oxidation and using a more detailed approach. A set of non-linear algebraic equations is obtained and solved to determine the burning rates, pyrolysis lengths and temperature profiles of smoldering cigarettes. The influence coefficients of several parameters on smolder characteristics are calculated.

\section{NOMENCLATURE}

$B_{s} \quad=$ smoldering transfer number, $\mathrm{W} / \mathrm{m}^{2} / \mathrm{K}$

$c_{p, i}=$ specific heat of solid or gas $i=f, d, c, v, w, \mathrm{~kJ} / \mathrm{kg} / \mathrm{K}$

$\bar{c}_{p, i} \quad=$ average specific heat of zone $i=f, d, c, \mathrm{~kJ} / \mathrm{kg} / \mathrm{K}$

$d_{p, i} \quad=$ average pore diameter in zone $i=f, d, c, \mathrm{~m}$

$E_{i} \quad=$ energy required to heat solid or gas $i=f, d, c, a, v, w, \mathrm{~J}$

$h_{o} \quad=$ convection heat transfer coefficient without blowing, $\mathrm{W} / \mathrm{m}^{2} / \mathrm{K}$

$h_{s}=$ convection heat transfer coefficient at smoldering front, $\mathrm{W} / \mathrm{m}^{2} / \mathrm{K}$

$h_{i, \text { conv }}=$ convection heat transfer coefficient around zone $i=f, d, c, \mathrm{~W} / \mathrm{m}^{2} / \mathrm{K}$

$h_{i, \text { rad }}=$ radiation heat transfer coefficient around zone $i=f, d, c, \mathrm{~W} / \mathrm{m}^{2} / \mathrm{K}$

$h_{i}^{*} \quad=$ effective heat convection coefficients around zone $i=f, d, c, \mathrm{~W} / \mathrm{m}^{2} / \mathrm{K}$

$\dot{m}_{i}^{\prime \prime} \quad=$ mass production or comsumption rate of solid or gas $i=f, d, c, a, v, w, \mathrm{~kg} / \mathrm{s} / \mathrm{m}^{2}$

$Q_{s} \quad=$ heat of smoldering, $\mathrm{J} / \mathrm{kg}$

$Q_{P} \quad=$ heat of pyrolysis, $\mathrm{J} / \mathrm{kg}$

$Q_{w} \quad=$ heat of vaporization of water, $\mathrm{J} / \mathrm{kg}$

$\dot{q}_{w}^{\prime \prime} \quad=$ heat flux to pre-heat and vaporize water, $\mathrm{W} / \mathrm{m}^{2}$

$\dot{q}_{v}^{\prime \prime} \quad=$ heat flux to pyrolyse dry fuel, $\mathrm{W} / \mathrm{m}^{2}$

$\dot{q}_{s}^{\prime \prime} \quad=$ heat flux at smoldering front, $\mathrm{W} / \mathrm{m}^{2}$

$\dot{q}_{c o n v}^{\prime \prime} \quad=$ heat flux lost by convection, $\mathrm{W} / \mathrm{m}^{2}$

$\dot{q}_{\text {rad }}^{\prime \prime}=$ heat flux by radiation, $\mathrm{W} / \mathrm{m}^{2}$

$T_{\max , i}=$ maximum temperature in zone $i=f, d, c, \mathrm{~K}$

$U=$ smoldering rate, $\mathrm{m}$

$T_{i} \quad=$ temperature, $\mathrm{K}$

$x_{d} \quad=$ drying front position, $\mathrm{m}$

$x_{s} \quad=$ smoldering front position, $\mathrm{m}$

$Y_{O 2, \mathrm{~s}}=$ mass fraction of oxygen at smoldering surface

$Y_{O 2, \infty}=$ ambient mass fraction of oxygen

$\alpha_{i} \quad=$ effective heat diffusivity of zone $i=f, d, c$,

$$
\alpha_{i}=\lambda_{i}^{*} /\left(\bar{\rho}_{i} \bar{c}_{p, i}\right), \mathrm{m}^{2} / \mathrm{s}
$$

$\beta=\mathrm{O} / \mathrm{F}$ stoichiometric mass ratio

$\gamma_{i}=$ effective convection coefficient around zone

$$
i=f, d, c, \gamma_{i}=4 h_{i}^{*} /\left(\rho_{i} c_{p, i} d\right), 1 / \mathrm{s}
$$

$\varepsilon_{s} \quad=$ emissivity of the smoldering surface

$\phi_{i} \quad=$ porosity of zone $i=f, d, c$

$\lambda_{g, i}=$ gas phase thermal conductivity in zone $i=f, d, c$, $\mathrm{W} / \mathrm{m} / \mathrm{K}$

$\lambda_{s, i}=$ solid thermal conductivity in zone $i=f, d, c, \mathrm{~W} / \mathrm{m} / \mathrm{K}$

$\lambda_{i}^{*}=$ effective heat conductivities in zone $i=f, d, c$,
$\mathrm{W} / \mathrm{m} / \mathrm{K}$

$\rho_{i} \quad=$ density of solid $i=f, d, c, a, \mathrm{~kg} / \mathrm{m}^{3}$

$\bar{\rho}_{i} \quad=$ average density of zone $i=f, d, c, \mathrm{~kg} / \mathrm{m}^{3}$

$\sigma=$ Stefan-Boltzmann constant $\left(=5.67 \times 10^{-8}\right), \mathrm{W} / \mathrm{m}^{2} / \mathrm{K}^{4}$

\section{Subscripts}

$a \quad=$ ash, average

$b \quad=$ vaporization, boiling

c $\quad=$ char

d $=$ dry tobacco

$f=$ virgin tobacco

$l=$ liquid water

$\max =$ maximum

$P \quad=$ pyrolysis

$s \quad=$ smoldering surface

$v \quad=$ volatiles

$w \quad=$ water vapour

$0=$ initial condition

$\infty \quad=$ ambient condition

\section{MODEL DESCRIPTION}

Figure 1 shows a schematic of a smoldering cigarette. The main hypotheses assumed in the present analysis are: 1)1D problem; 2) no drawing; 3) steady state (semi-infinite cigarette); 4) infinitesimaly thin fronts of drying, pyrolysis and char oxidation; 5) volatiles and tar exit through the smoldering end without reacting with the char; 6) ash zone does not affect the flow; 7) char is pure carbon (except for the ash content); 8) thermal equilibrium between solid and gas; 9) paper burns at the same rate as the tobacco; and (10) oxygen diffusion through the paper is negligible.

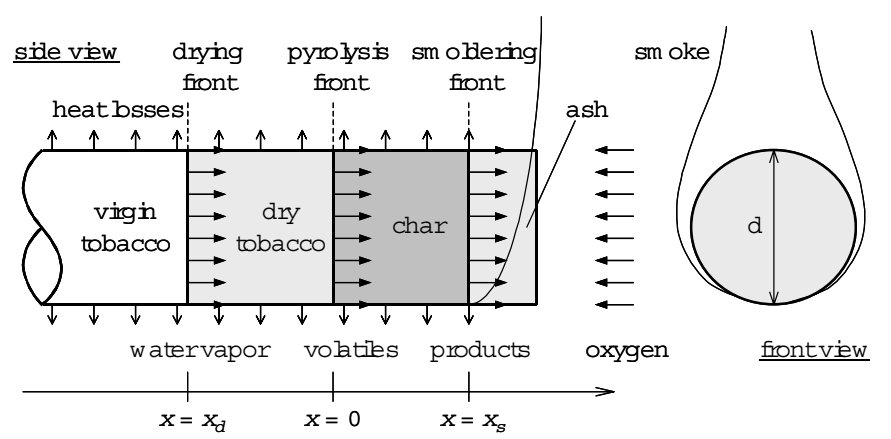

Fig. 1 One-dimensional smoldering of a cigarette

The drying front, determined by a boiling or vaporization temperature, $T_{b}(\sim 373 \mathrm{~K})$, is located at $x=x_{d}(<0)$; the pyrolysis front, determined by a pyrolysis temperature, $T_{P}$, is located at $x=0$; while the smoldering front, determined by a smoldering temperature, $T_{s}$, is located at $x=x_{s}(>0)$.

\section{Energy Equations for the Cigarette}

The initial temperature within the cigarette is $T_{\mathrm{o}}=T_{\infty}$. There is no reaction inside the char zone, but only on its boundaries. 
The energy equation is solved first for the char zone, $0<x<x_{\mathrm{s}}$, and then coupled to the energy equations for the preheating zone, $x<x_{d}$, and for the drying zone, $x_{d}<x<0$.

Considering a reference frame moving with the reaction fronts, and using control volumes of infinitesimal thickness inside the virgin tobacco, dry tobacco and char zones, it follows that the energy equations can be written as:

Virgin tobacco zone $\left(-\infty<x<x_{d}\right)$ :

$$
\dot{m}_{f}^{\prime \prime} c_{p, f} \frac{d T}{d x}=\lambda_{f}^{*} \frac{d^{2} T}{d x^{2}}-\frac{4 h_{f}^{*}}{d}\left(T-T_{0}\right)
$$

Dry tobacco zone $\left(x_{d}<x<0\right)$ :

$$
\left(\dot{m}_{d}^{\prime \prime} c_{p, d}+\dot{m}_{w}^{\prime \prime} c_{p, w}\right) \frac{d T}{d x}=\lambda_{d}^{*} \frac{d^{2} T}{d x^{2}}-\frac{4 h_{d}^{*}}{d}\left(T-T_{0}\right)
$$

\section{Char zone $\left(0<x<x_{s}\right)$ :}

$\left(\dot{m}_{c}^{\prime \prime} c_{p, c}+\dot{m}_{a}^{\prime \prime} c_{p, a}+\dot{m}_{v}^{\prime \prime} c_{p, v}+\dot{m}_{w}^{\prime \prime} c_{p, w}\right) \frac{d T}{d x}=\lambda_{c}^{*} \frac{d^{2} T}{d x^{2}}-\frac{4 h_{c}^{*}}{d}\left(T-T_{0}\right)$

where $\dot{m}_{i}^{\prime \prime}(i=f, d, c, w, v)$ are the mass consumption - or production - rates of virgin fuel, dry fuel, char, water vapor and volatiles, respectively; $\lambda_{i}^{*}(i=f, d, c)$ are the effective heat conductivities in the unburned fuel, dry fuel, and char zones, respectively; and $h_{i}^{*}(i=f, d, c)$ are the effective heat convection coefficients around unburned fuel, dry fuel, and char zones. The char zone includes ash inside.

The mass fluxes are $\dot{m}_{f}^{\prime \prime}=\rho_{f} U, \dot{m}_{d}^{\prime \prime}=\rho_{d} U, \dot{m}_{c}^{\prime \prime}=\rho_{c} U$, $\dot{m}_{a}^{\prime \prime}=\rho_{a} U, \dot{m}_{w}^{\prime \prime}=\left(\rho_{f}-\rho_{d}\right) U$ and $\dot{m}_{v}^{\prime \prime}=\left(\rho_{d}-\rho_{c}-\rho_{a}\right) U$, where $U$ is the smoldering rate.

It is assumed that gas and solid phases are in thermal equilibrium. The effective heat conductivities include a conduction term and an internal radiation term:

$$
\begin{aligned}
& \lambda_{i}^{*}=\lambda_{i, \text { cond }}+\lambda_{i, \text { rad }} \quad ; \quad i=f, d, c \\
& \lambda_{i, \text { cond }}=\left(1-\phi_{i}\right) \lambda_{s, i}+\phi_{i} \lambda_{g, i} \\
& \lambda_{i, \text { rad }}=\frac{16}{3} \sigma d_{p, i} T_{\text {max }, i}^{3}
\end{aligned}
$$

where $\phi_{i}$ is the porosity of zone $i, d_{p, i}$ is the average pore diameter in zone $i, \lambda_{s, i}$ is the solid thermal conductivity in zone $i, \lambda_{g, i}$ is the gas phase thermal conductivity in zone $i, T_{\max , i}$ is the maximum temperature in zone $i$ and $\sigma$ is the StefanBoltzmann constant.

The effective heat transfer coefficient along zone $i, h_{i}^{\prime}$, assumed as a constant, is given by

$$
h_{i}^{*}=h_{i, c o n v}+h_{i, \text { rad }} \quad ; \quad i=f, d, c
$$

$$
h_{i, r a d} \cong \varepsilon_{i} \sigma\left(T_{a, i}+T_{\infty}\right)\left(T_{a, i}^{2}+T_{\infty}^{2}\right)
$$

where $h_{i, c o n v}$ is the convection heat transfer coefficient, $h_{i, r a d}$ is the radiation heat transfer coefficient and $\varepsilon_{i}$ are emissivities of the $i$ zone surface. $T_{a, i}(i=f, d, c)$ are average temperatures of the unburned fuel, dry fuel and char zones, respectively, and are given by:

$$
T_{a, f}=0.5\left(T_{\infty}+T_{b}\right), T_{a, d}=0.5\left(T_{b}+T_{P}\right), T_{a, c}=0.5\left(T_{s}+T_{P}\right)(9)
$$

The convective heat transfer coefficients are obtained from literature in terms of the Grashof, Prandtl and Nusselt numbers for natural convection around horizontal cylinders. The values calculated around the virgin fuel, dry fuel and char region are about 16,30 and $73 \mathrm{~W} / \mathrm{m}^{2} / \mathrm{K}$, respectively. Gann et al. [7] used a single value for all regions, about $50 \mathrm{~W} / \mathrm{m}^{2} / \mathrm{K}$.

The heat transfer coefficient in the boundary layer adjacent to the smoldering surface, with correction for blowing, is calculated from

$$
h_{s}=h_{0}\left(1 / B_{s}\right) \ln \left(1+B_{s}\right)
$$

where $h_{s}$ and $h_{\mathrm{o}}$ are the heat transfer coefficients with and without blowing, respectively, at the smoldering surface, and $B_{s}$ is the mass transfer number for smoldering combustion:

$$
B_{s}=\frac{Y_{O 2, \infty}-Y_{O 2, s}}{\beta \rho_{c} / \rho_{f}+Y_{O 2, s}}
$$

where $Y_{O 2, \infty}$ is the oxygen mass fraction in the ambient, $Y_{O 2, s}$ is the oxygen mass fraction at the smoldering surface, $\rho_{f}$ is the cigarette density and $\rho_{c}$ is the char density.

For high smoldering surface temperatures, the combustion process is diffusion controlled and it can be assumed $Y_{O 2, s}=0$.

\section{Chemical Reactions}

Pyrolysis of tobacco and other cellulosic materials produces a reactive char through a complex interplay of chemistry, heat and mass transfer. The char oxidation process involves chemisorption of oxygen in the reactive sites of the char, which is highly exothermic and takes place at relatively low temperatures, to form surface oxides.

Following Kanury and Holve [10], it is assumed that pyrolysis occurs at a fixed temperature, $T=T_{P}$, through the single step reaction:

$$
\text { tobacco } \rightarrow \text { volatiles }+ \text { char }+Q_{P}
$$

where $Q_{P}$ is the heat of pyrolysis.

In the present analysis the char is assumed to be made of pure carbon (however the char zone contains pure carbon and ash). The primary surface reactions for char oxidation are:

$$
\begin{aligned}
& \mathrm{C}+\mathrm{O}_{2} \rightarrow \mathrm{CO}_{2}+393965 \mathrm{~kJ} / \mathrm{kmol} \\
& \mathrm{C}+0.5 \mathrm{O}_{2} \rightarrow \mathrm{CO}+218614 \mathrm{~kJ} / \mathrm{kmol}
\end{aligned}
$$


A general chemical equation for the primary surface equations can be written as

$$
\mathrm{C}+\mathrm{aO}_{2} \rightarrow(2-2 a) \mathrm{CO}+(2 a-1) \mathrm{CO}_{2}+Q_{s}
$$

where $Q_{s}=218614(2-2 a)+393965(2 a-1) \mathrm{kJ} / \mathrm{kmol}$ is the heat of smoldering, with $1 / 2<a<1$.

The oxidizer/fuel mass ratio for reaction (R4) is $\beta=8 a / 3$, which varies from $4 / 3$ to $8 / 3$ and indicates the proportion of $C O$ and $\mathrm{CO}_{2}$ being produced. According to Muramatsu [5,6] data about 7 moles of $\mathrm{CO}_{2}$ are produced for each mol of $\mathrm{CO}$ during natural smoldering of cigarettes, however this proportion includes the products from pyrolysis and char oxidation. Their bomb calorimeter measurements indicate a heat of smoldering $Q_{s} \approx 18 \mathrm{MJ} / \mathrm{kg}$ for tobacco, with incomplete conversion $(\sim 60$ $\%$ ) of carbon to $\mathrm{CO}$ and $\mathrm{CO}_{2}$.

\section{Simplified Energy Equations}

The energy equations (1-3) can be rewritten as:

$$
\begin{aligned}
& \alpha_{i} \frac{d^{2} T}{d x^{2}}-U \frac{d T}{d x}-\gamma_{i}\left(T-T_{0}\right)=0 \quad ; \quad i=f, d, c \\
& \alpha_{i}=\lambda_{i}^{*} /\left(\bar{\rho}_{i} \bar{c}_{p, i}\right) \\
& \gamma_{i}=4 h_{i}^{*} /\left(\rho_{i} c_{p, i} d\right)
\end{aligned}
$$

where $\alpha_{i}$ is the effective heat diffusivity in zone $i$ and $\gamma_{i}$ is the effective heat convection coefficient around zone $i$.

The average heat capacities, $\bar{\rho}_{i} \bar{c}_{p, i}$, are calculated by

$$
\begin{aligned}
& \bar{\rho}_{f} \bar{c}_{p, f}=\rho_{f} c_{p, f} \\
& \bar{\rho}_{d} \bar{c}_{p, d}=\rho_{d} c_{p, d}+\left(\rho_{f}-\rho_{d}\right) c_{p, w} \\
& \bar{\rho}_{c} \bar{c}_{p, c}=\rho_{c} c_{p, c}+\rho_{a} c_{p, a}+\left(\rho_{f}-\rho_{d}\right) c_{p, w}+\left(\rho_{d}-\rho_{c}-\rho_{a}\right) c_{p, v}
\end{aligned}
$$

where $\bar{\rho}_{i}, i=f, d, c$, is the average density of zone $i, \rho_{i}, i=f$, $d, c, a$ is the density of solid $i, \bar{c}_{p, i}, i=f, d, c$, is the average specific heat of zone $i$, and $c_{p, i}, i=f, d, c, v, w$, is the specific heat of solid or gas $i$.

\section{Boundary and Coupling Conditions}

The following boundary and coupling conditions are used in the problem:

$$
\begin{aligned}
& T(-\infty)=T_{0}, \quad T\left(x_{d}\right)=T_{b} \\
& T(0)=T_{P}, \quad T\left(x_{s}\right)=T_{s} \\
& \lambda_{f}^{*} T_{x}\left(x_{d}^{-}\right)=\lambda_{d}^{*} T_{x}\left(x_{x_{d}}^{+}\right)+\dot{q}_{w}^{\prime \prime}
\end{aligned}
$$

$$
\begin{aligned}
& \lambda_{d}^{*} T_{x}\left(0^{-}\right)=\lambda_{c}^{*} T_{x}\left(0^{+}\right)+\dot{q}_{v}^{\prime \prime} \\
& \lambda_{c}^{*} T_{x}\left(x_{s}^{-}\right)=\dot{q}_{s}^{\prime \prime}
\end{aligned}
$$

where $\dot{q}_{w}^{\prime \prime}$ is the heat flux to pre-heat and vaporize water in the virgin wood, $\dot{q}_{v}^{\prime \prime}$ is the heat flux to pyrolyse the dry fuel, $\dot{q}_{s}^{\prime \prime}$ is the heat flux for char oxidation at the smoldering front, $\dot{q}_{c o n v}^{\prime \prime}$ is the heat flux lost by convection and $\dot{q}_{\text {rad }}^{\prime \prime}$ is the heat flux by radiation. The heat fluxes $\dot{q}_{w}^{\prime \prime}, \dot{q}_{v}^{\prime \prime}$ and $\dot{q}_{s}^{\prime \prime}$ are calculated, respectively, from:

$$
\begin{aligned}
& \dot{q}_{w}^{\prime \prime}=\dot{m}_{w}^{\prime \prime}\left(Q_{w}-c_{p, l}\left(T_{b}-T_{0}\right)\right) \\
& \dot{q}_{v}^{\prime \prime}=\dot{m}_{v}^{\prime \prime} Q_{P} \\
& \dot{q}_{s}^{\prime \prime}=\dot{m}_{c}^{\prime \prime} Q_{s}-\dot{q}_{c o n v}^{\prime \prime}+\dot{q}_{r a d}^{\prime \prime}
\end{aligned}
$$

where $Q_{s}$ is the heat of smoldering, $Q_{P}$ is the heat of pyrolysis and $Q_{w}(<0)$ is the heat of vaporization of water.

Heat can be lost by radiation or absorbed from another source, for example, a laser beam or nearby burning materials. If there is only heat loss by radiation to the ambient, it is given by

$$
\dot{q}_{r a d}^{\prime \prime}=-\varepsilon_{s} \sigma\left(T_{s}^{4}-T_{\infty}^{4}\right)
$$

where $\varepsilon_{s}$ is the emissivity of the smoldering surface.

\section{Solution of the equations}

To solve the problem it is required the calculation of 9 variables: 6 integration constants, drying front position, $x_{d}$, smoldering front position, $x_{s}$, and smoldering rate, $U$.

Solution for the problem with no circumferential heat losses $\left(\gamma_{i}=0\right)$ is obtained by integration of the governing equations (12a) with the boundary/coupling conditions (14a-e).

An expression for the smoldering rate $U$ is obtained:

$$
U=\frac{h_{s}\left(T_{s}-T_{\infty}\right)+\varepsilon_{s} \sigma\left(T_{s}^{4}-T_{\infty}^{4}\right)}{\rho_{c} Q_{s}-E_{f}-E_{d}-E_{c}-E_{a}-E_{w}-E_{v}}
$$

where $E_{f}=\rho_{f} c_{p, f}\left(T_{b}-T_{0}\right)$ is the energy to heat fuel to boiling temperature, $E_{d}=\rho_{d} c_{p, d}\left(T_{P}-T_{b}\right)$ is the energy to heat the dry fuel to pyrolysis temperature, $E_{c}=\rho_{c} c_{p, c}\left(T_{s}-T_{P}\right)$ is the energy to heat char to smoldering temperature, $E_{a}=\rho_{a} c_{p, a}\left(T_{s}-T_{P}\right)$ is the energy to heat ash to smoldering temperature, $\left.\left.E_{w}=\left(\rho_{f}-\rho_{d}\right)\right) c_{p, l}\left(T_{b}-T_{0}\right)+c_{p, w}\left(T_{s}-T_{b}\right)-Q_{w}\right]$ is the energy to vaporize water, and $\left.E_{v}=\left(\rho_{d}-\rho_{c}-\rho_{a}\right) \mid c_{p, v}\left(T_{s}-T_{P}\right)-Q_{P}\right\rfloor$ is the energy to pyrolyse and heat volatiles.

The denominator of Eq. (22) is the net energy to sustain the smoldering process and the numerator corresponds to the heat losses at the smoldering surface. Therefore, the net energy 
released multiplied by the burn rate is equal to the heat losses per unit time.

It can be seen that if $\rho_{c} Q_{s}>\sum E_{i}$, then $U>0$. Otherwise, if $\rho_{c} Q_{s}<\sum E_{i}$, external energy has to be added to sustain the smoldering process.

The burn rate $U$ can be calculated as a function of smolder temperature $T_{s}$. Alternatively, if the smolder rate $U$ is known, or is measured, $T_{s}$ can be calculated.

Analytical expressions for the drying front and smoldering front positions can be easily obtained, assuming no circumferential heat losses.

For the problem with circumferential heat losses, the following expressions for temperature profiles are obtained:

$$
\begin{aligned}
& T=T_{o}+\left(T_{b}-T_{o}\right) e^{\frac{U\left(1+\Delta_{f}\right)\left(x-x_{d}\right)}{2 \alpha_{f}}} ; \quad-\infty<x<x_{d} \\
& T=T_{o}+C_{1, d} e^{\frac{U\left(1+\Delta_{d}\right) x}{2 \alpha_{d}}}+C_{2, d} e^{\frac{U\left(1-\Delta_{d}\right) x}{2 \alpha_{d}}} ; \quad x_{d}<x<0 \\
& T=T_{o}+C_{1, c} e^{\frac{U\left(1+\Delta_{c}\right) x}{2 \alpha_{c}}}+C_{2, c} e^{\frac{U\left(1-\Delta_{c}\right) x}{2 \alpha_{c}}} ; \quad 0<x<x_{s}
\end{aligned}
$$

where $C_{1, c}, C_{1, d}, C_{2, c}$ and $C_{2, d}$ are constants (dependent on $U, x_{d}$ and $\left.x_{s}\right)$, with

$$
\Delta_{i}=\sqrt{1+4 \frac{\alpha_{i} \gamma_{i}}{U^{2}}} ; \quad i=f, d, c
$$

Matching the coupling conditions at $x=x_{d}, x=x_{s}$ and $x=0$ gives, respectively:

$$
\begin{aligned}
& \left(\frac{\lambda_{f}^{*}}{\alpha_{f}}\left(T_{b}-T_{0}\right)\left(1+\Delta_{f}\right)-2 \frac{\dot{q}_{w}^{\prime \prime}}{U}\right) \frac{\alpha_{d}}{\lambda_{d}^{*}}= \\
& =C_{1, d}\left(1+\Delta_{d}\right) e^{\frac{U\left(1+\Delta_{d}\right) x_{d}}{2 \alpha_{d}}}+C_{2, d}\left(1-\Delta_{d}\right) e^{\frac{U\left(1-\Delta_{d}\right) x_{d}}{2 \alpha_{d}}} \\
& 2 \frac{\alpha_{c}}{\lambda_{c}^{*}} \frac{\dot{q}_{s}^{\prime \prime}}{U}=C_{1, c}\left(1+\Delta_{c}\right) e^{\frac{U\left(1+\Delta_{c}\right) x_{s}}{2 \alpha_{c}}}+C_{2, c}\left(1-\Delta_{c}\right) e^{\frac{U\left(1-\Delta_{c}\right) x_{s}}{2 \alpha_{c}}} \\
& \frac{\lambda_{d}^{*}}{\alpha_{d}}\left(C_{1, d}\left(1+\Delta_{d}\right)+C_{2, d}\left(1-\Delta_{d}\right)\right)= \\
& =\frac{\lambda_{c}^{*}}{\alpha_{c}}\left(C_{1, c}\left(1+\Delta_{c}\right)+C_{2, c}\left(1-\Delta_{c}\right)\right)+2 \frac{\dot{q}_{v}^{\prime \prime}}{U}
\end{aligned}
$$

Solution of this set of non-linear algebraic equations, yields the drying front position, smoldering front position and the burn rate. The influence of effective heat diffusivities and burn velocities on temperature profiles and other smoldering characteristics can be directly observed in Eqs. (23-29).

Analytical expressions for the sensitivity coefficients of smolder rates, $\varepsilon_{i}=\left(\phi_{i} / U\right)\left(\partial U / \partial \phi_{i}\right), i=M, T_{p}, Q_{p}, d, T_{o}, Q_{s}, r_{c}, r_{f}$, $T_{s}$, etc., can be derived from Eq. (22), for smolder with no circumferential heat losses, and from Eqs. (27-29), for smolder with circumferential heat losses. Expressions of sensitivity coefficients for other variables can also be obtained.

\section{RESULTS}

Using Eqs. (23-29) a number of plots was obtained, showing the influence of variations of several parameters, such as smoldering temperatures, heat losses, pyrolysis temperature and heat of smoldering on burning velocities, smoldering front and drying front positions.

Table 1 shows experimental data for several tobacco types obtained by Muramatsu [5], at $T_{a m b}=293 \mathrm{~K}$. The last column of Table 1 shows the ratios of cigarette packing densities when pyrolysis is supposed to be completed, at $T \sim 750 \mathrm{~K}$. According to Muramatsu data, above $750 \mathrm{~K}$ the volumetric char oxidation starts and reduces char densities to about $20 \%$ of the initial values at maximum temperatures of about $1100 \mathrm{~K}$ for all cigarettes.

Table 2 shows reference data used in the simulations, with plots presented in Figs. 2-4. Data were based on several references: Muramatsu [5,6], Kanury and Holve [10] and Kung and Kalelkar [11].

\section{Table 1 - Experimental data for free burning cigarettes obtained by Muramatsu [5]}

\begin{tabular}{|c|c|c|c|c|}
\hline Tobacco & $\begin{array}{c}\text { Packing } \\
\text { density } \\
\left(\mathrm{kg} / \mathrm{m}^{3}\right)\end{array}$ & $\begin{array}{c}\text { Water } \\
\text { content, dry } \\
\text { basis }(\%)\end{array}$ & $\begin{array}{c}\text { Max. } \\
\text { Temp. } \\
(\mathrm{K})\end{array}$ & $\begin{array}{c}\rho_{c} / \rho_{f} \\
(750 \mathrm{~K})\end{array}$ \\
\hline Flue cured & 281 & 13.11 & 1090 & 0.52 \\
\hline Burley & 256 & 10.90 & 1100 & 0.55 \\
\hline Matsukawa 1 & 210 & 11.34 & 1090 & 0.63 \\
\hline Matsukawa 2 & 239 & 11.34 & 1095 & 0.63 \\
\hline Matsukawa 3 & 293 & 11.34 & 1100 & 0.63 \\
\hline
\end{tabular}

Table 3 compares theoretical burn rates with experimental ones from Muramatsu [5,6], using data from Table 1. It was assumed $Q_{s}=22 \mathrm{MJ} / \mathrm{kg}, T_{P}=650 \mathrm{~K}$ and ash content of $10 \%$ of the virgin tobacco in all cases.

There was a good agreement between theoretical burning rates and experimental ones, with differences less than $5 \%$, except for the flue cured tobacco, probably because differences on heat of smoldering were not considered. Distances between smoldering and drying fronts are about $4 \mathrm{~mm}$ in all cases, which is approximately a half of the experimental lengths. It should be noted that some previous models of cigarette smoldering have not found steady state values or have assumed known values of burn rates in order to determine temperature distributions $[5,6,7,8]$. For a better description of temperature profiles a distributed reaction zone should be considered.

It can be seen in figure 2 that circumferential heat losses cause a decrease of about $150 \mathrm{~K}$ on smolder temperatures in both cases: $Q_{s}=20$ and $25 \mathrm{MJ} / \mathrm{kg}$, for a fixed smolder rate. As expected, when the heat of smoldering is increased, keeping a constant burn rate and considering circumferential heat losses, there is an increase in smoldering temperatures (for $U=4$ $\mathrm{mm} / \mathrm{min}, T_{s}$ increases from $1025 \mathrm{~K}$ to $1100 \mathrm{~K}$, for $Q_{s}=20$ and $25 \mathrm{MJ} / \mathrm{kg}$, respectively).

It is also observed in figure 2 that pyrolysis temperature, $T_{P}$, has no significant effect on burn rates, but has strong influence on fronts' positions if no circumferential heat losses are considered, as showed in figures 3 and 4 . Thus, the use of 
appropriate circumferential convective heat transfer coefficients is essential to obtain correct smolder rates in cigarettes.

Table 2 - Reference data used in the simulations

\begin{tabular}{|c|r|r|r|r|r|}
\hline Property & \multicolumn{1}{|c|}{ Value } & \multicolumn{1}{c|}{ Units } & Property & \multicolumn{1}{c|}{ Value } & Units \\
\hline$Q_{P}$ & -300 & $\mathrm{~kJ} / \mathrm{kg}$ & $T_{b}$ & 373 & $\mathrm{~K}$ \\
\hline$Q_{s}$ & 22 & $\mathrm{MJ} / \mathrm{kg}$ & $T_{P}$ & 600 & $\mathrm{~K}$ \\
\hline$Q_{w}$ & $-2,445$ & $\mathrm{~kJ} / \mathrm{kg}$ & $T_{o}$ & 293 & $\mathrm{~K}$ \\
\hline$c_{p, f}$ & 2.50 & $\mathrm{~kJ} / \mathrm{kg} / \mathrm{K}$ & $T_{\infty}$ & 293 & $\mathrm{~K}$ \\
\hline$c_{p, c}$ & 0.67 & $\mathrm{~kJ} / \mathrm{kg} / \mathrm{K}$ & $\varepsilon_{f}$ & 0.97 & - \\
\hline$c_{p, v}$ & 1.10 & $\mathrm{~kJ} / \mathrm{kg} / \mathrm{K}$ & $\varepsilon_{d}$ & 0.97 & - \\
\hline$c_{p, w}$ & 2.02 & $\mathrm{~kJ} / \mathrm{kg} / \mathrm{K}$ & $\varepsilon_{c}$ & 0.97 & - \\
\hline$c_{p, l}$ & 4.17 & $\mathrm{~kJ} / \mathrm{kg} / \mathrm{K}$ & $\phi_{f}$ & 0.82 & - \\
\hline$\lambda_{c}$ & 0.041 & $\mathrm{~W} / \mathrm{m} / \mathrm{K}$ & $\phi_{d}$ & 0.82 & - \\
\hline$\lambda_{f}$ & 0.147 & $\mathrm{~W} / \mathrm{m} / \mathrm{K}$ & $\phi_{c}$ & 0.90 & - \\
\hline$\lambda_{v}$ & 0.043 & $\mathrm{~W} / \mathrm{m} / \mathrm{K}$ & $d_{p, f}$ & 0.0003 & $\mathrm{~m}$ \\
\hline$\lambda_{w}$ & 0.047 & $\mathrm{~W} / \mathrm{m} / \mathrm{K}$ & $d_{p, d}$ & 0.0003 & $\mathrm{~m}$ \\
\hline$\rho_{f}$ & 250 & $\mathrm{~kg} / \mathrm{m}^{3}$ & $d_{p, c}$ & 0.0006 & $\mathrm{~m}$ \\
\hline$\rho_{d}$ & 225 & $\mathrm{~kg} / \mathrm{m}^{3}$ & $Y_{O 2, \infty}$ & 0.23 & - \\
\hline$\rho_{c}$ & 112 & $\mathrm{~kg} / \mathrm{m}^{3}$ & $Y_{O 2, s}$ & 0 & - \\
\hline$\rho_{a}$ & 25 & $\mathrm{~kg} / \mathrm{m}^{3}$ & $M$ & 10 & $\%$ \\
\hline
\end{tabular}

Table 3 - Theoretical results and comparison with experiments

\begin{tabular}{|l|c|c|c|c|c|}
\hline \multicolumn{1}{|c|}{ Tobacco } & $\begin{array}{c}x_{d} \\
(\text { theo. }) \\
(\mathrm{mm})\end{array}$ & $\begin{array}{c}x_{s} \\
(\text { theo. }) \\
(\mathrm{mm})\end{array}$ & $\begin{array}{c}U \\
(\mathrm{exp} .) \\
(\mathrm{mm} / \mathrm{min})\end{array}$ & $\begin{array}{c}U \\
(\text { theo. }) \\
(\mathrm{mm} / \mathrm{min})\end{array}$ & $\begin{array}{c}\text { Error } \\
(\%)\end{array}$ \\
\hline Flue cured & -1.57 & 2.30 & 2.65 & 3.44 & +29.8 \\
\hline Burley & -1.66 & 2.39 & 3.80 & 3.66 & -3.68 \\
\hline Matsukawa 1 & -1.82 & 2.42 & 3.79 & 3.76 & -0.79 \\
\hline Matsukawa 2 & -1.80 & 2.44 & 3.23 & 3.35 & +3.72 \\
\hline Matsukawa 3 & -1.79 & 2.47 & 2.87 & 2.78 & -3.13 \\
\hline
\end{tabular}

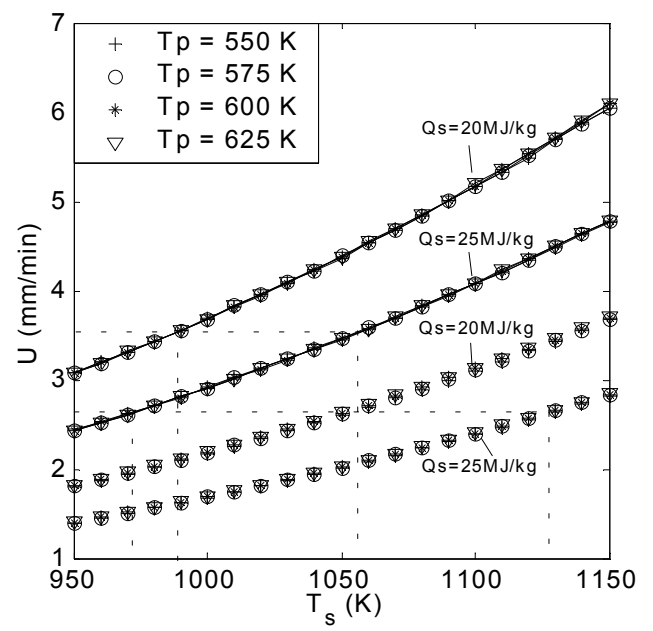

Fig. 2 Smoldering rates, $U$, vs smoldering temperatures, $T_{s}$, for $Q_{s}=20$ and $25 \mathrm{MJ} / \mathrm{kg}$, with circumferential heat losses (lines + symbols) and no circumferential heat losses (symbols)

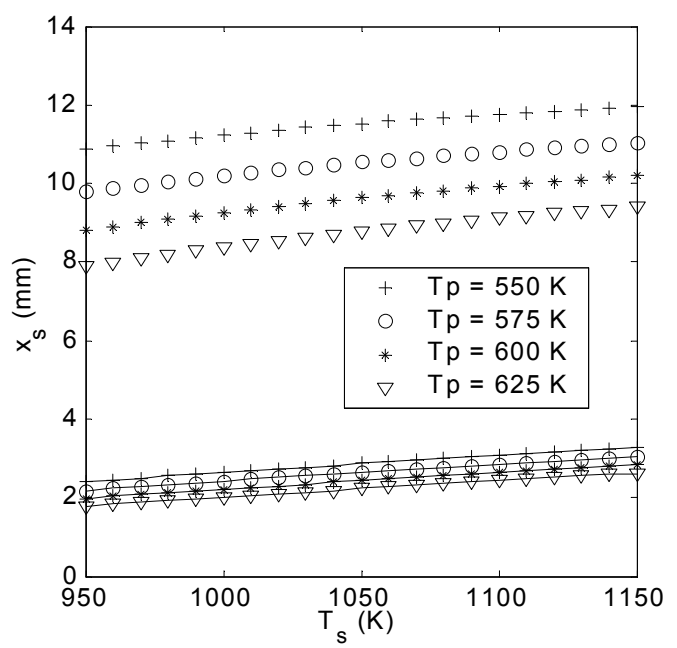

Fig. 3 Smoldering front position, $x_{s}$, vs smolder temperature, $T_{s}$, with circumferential heat losses (dotted lines + symbols) and no circumferential heat losses (symbols)

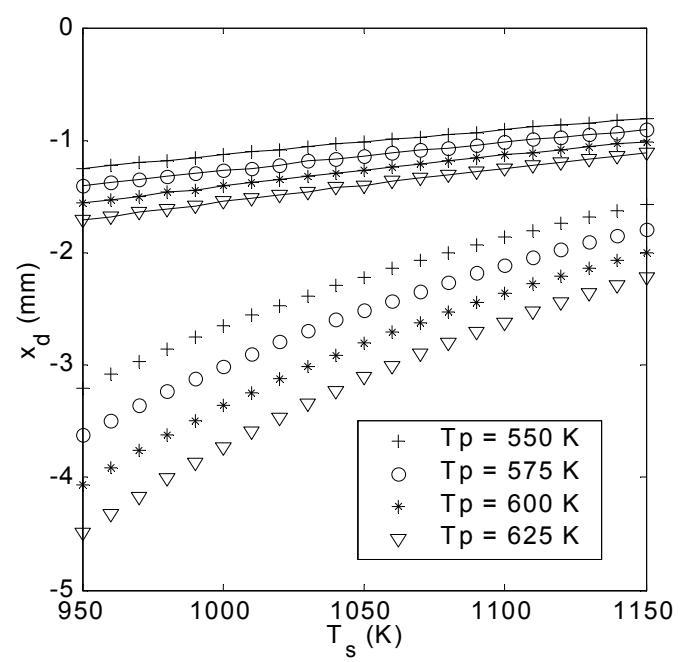

Fig. 4 Drying front position, $x_{d}$, vs smolder temperature, $T_{s}$, with circumferential heat losses (lines + symbols) and no circumferential heat losses (symbols)

The effects of parameter variations on burn rates and on distances between smolder and drying fronts are shown in Figs. 5,6 and 7, using the reference values shown on Table 1. The effects of variations of the tobacco packing density on burn rate was calculated assuming a constant ratio (50\%) between char and tobacco densities.

It can be observed in figures 5 and 6 that variations in moisture content, heat of pyrolysis and pyrolysis temperature (in the limits presented) have no significant influence on burn rates, while variations in cigarette diameters, densities, heat of smoldering and smoldering temperature have a significant influence on burn rates, which is, generaly, in agreement to the experimental and numerical results obtained by Muramatsu [5].

Figure 7 shows that pyrolysis and initial temperatures have a significant effect on smolder-drying fronts distance. 


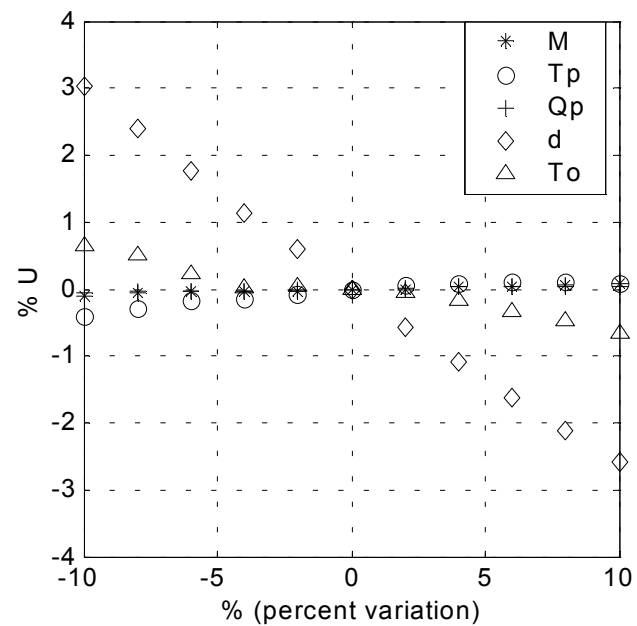

Fig. 5 Influence coefficients on smolder rates of cigarettes without draw

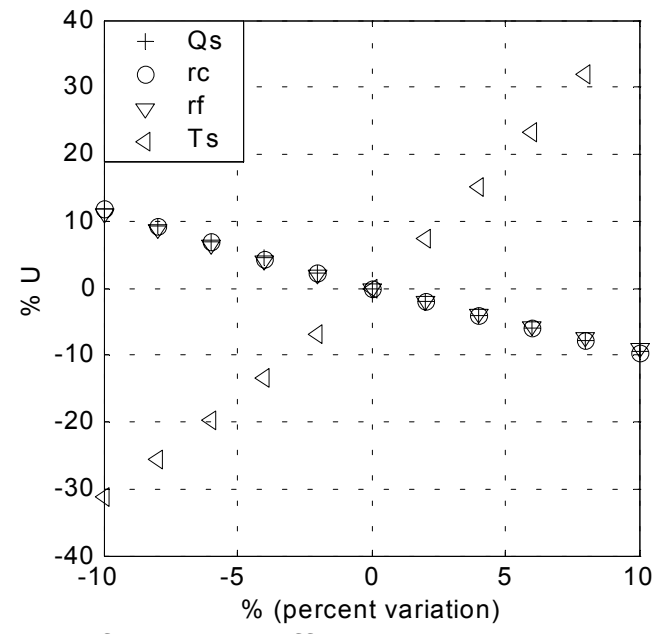

Fig. 6 Influence coefficients on smolder rates of cigarettes without draw

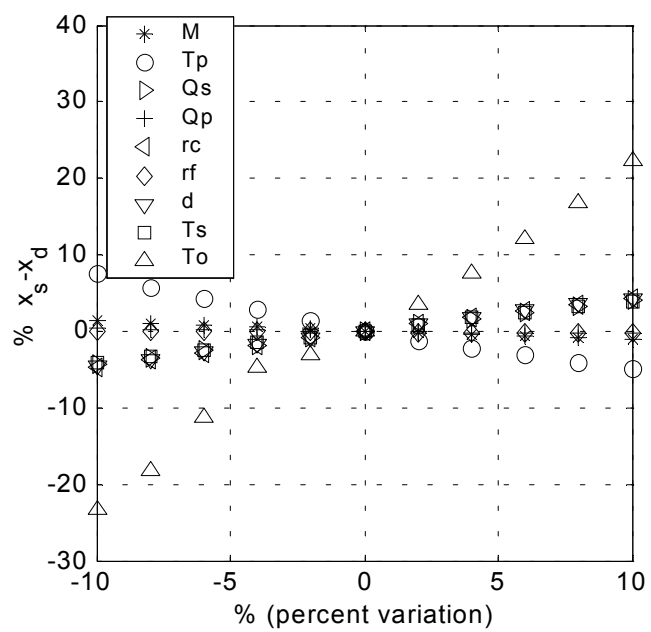

Fig. 7 Influence coefficients on smoldering-drying fronts distance of cigarettes without draw

Smolder temperatures have a strong influence on smolder rates and on smolder-drying fronts distance. They depend on oxygen diffusion into the boundary layer. According to experimental data from Muramatsu [5] there is a linear relation between ambient oxygen molar fraction and smoldering temperature for cigarette burning.

\section{CONCLUSIONS}

A simplified analytical model was developed to simulate free burning of cigarettes (no draw) and to study the effects of variations on several parameters, such as moisture, diameter, smoldering temperature, heat losses, pyrolysis temperature, heat of pyrolysis and heat of smoldering on smolder characteristics of cigarettes such as burn rates, temperature profiles, and positions of the smoldering and drying fronts. The model presented a good agreement with experimental burn rates, considering the simplifying assumptions.

\section{ACKNOWLEDGMENTS}

The author acknowledges the support of Fapesp and CNPq (Brazil) to this research.

\section{REFERENCES}

[1] Ohllemiller, T.J., Villa, K.M., Braun, E., Eberhardt, K.R., Harris-Jr, R.H., Lawason, J.R., Gann, R.G., "Quantifying the ignition propensity of cigarettes", Fire and Materials, Vol. 19, pp 155-169, 1995.

[2] Egerton, A., Gugan, K., Weinberg, F.J., "The mechanism of smoldering in cigarettes", Combustion and Flame: 7: 63-77, 1963.

[3] Gugan, K., "Natural smoulder in cigarettes", Combustion and Flame 10: 161-164, 1966.

[4] Summerfield, M., Ohlemiler, T.J., Sandusky, H.W., “A Thermophysical Mathematical Model of Steady-Draw Smoking and Predictions of Overall Cigarette Behavior", Combustion and Flame 33: 263-279, 1978.

[5] Muramatsu, M., Umemura, S., Okada, T., "A Mathematical Model of Evaporation-Pyrolysis Processes Inside a Naturally Smoldering Cigarette", Combustion and Flame, 36: 245-262, 1979.

[6] Muramatsu, M., "Studies on the Transport Phenomena in Naturally Smoldering Cigarettes", Scientific Papers of The Central Research Institute, no. 123, Japan Tobacco and Salt Public Corporation, 1981 (In Japanese).

[7] Gann, R.G., Harris Jr., R.H., Krasny, J.F., Levine, R.., Mitler, H. E., Ohlemiller, T.J., "The Effect of Cigarette Characteristics on the Ignition of Soft Furnishings", NBS Technical Note 1241, National Bureau of Standards, US Department of Commerce, 1988.

[8] Mitler, E., Walton, G.N., "Modeling the Ignition of Soft Furnishings by a Cigarette", NIST Special Publication 852, National Institute of Standards and Technology, 1993.

[9] Costa, F.S., "Smoldering of Cigarettes", $9^{\text {th }}$ Brazilian Congress of Thermal Engineering and Sciences, ENCIT 2002, CD-ROM, Caxambu, MG, Brazil, 2002.

[10] Kanury, A.M., Holve, D.J., "Transient Conduction with Pyrolysis (Approximate Solutions for Charring of Wood Slabs)", Transactions of the Asme, vol. 104: 338-343, 1982.

[11] Kung, H., Kalelkar, A.S., On the Heat of Reaction in Wood Pyrolysis, Combustion and Flame, 20: 91-103 (1973). 